\title{
Implementasi Case Based Reasoning Mendiagnosa Penyakit Stroke Menggunakan Algoritma Probabilistic Symmetric
}

\author{
Rizal Rachman \\ Universitas Adhirajasa Reswara Sanjaya \\ Jl. Sekolah Internasional No 1-6 Antapani, Bandung, Indonesia \\ e-mail: rizalrachman@ars.ac.id
}

\begin{tabular}{llll}
\hline Informasi Artikel Diterima: 02-06-2020 Direvisi: 28-07-2020 & Disetujui: 10-02-2021 \\
\hline
\end{tabular}

\begin{abstract}
Abstrak
Penyakit stroke merupakan salah satu penyakit yang cukup berbahaya di Indonesia. Penyakit yang diawali dengan tanda seperti mati rasa yang berada di wajah, kaki, lengan, ataupun di sisi salah satu tubuh, disertai dengan adanya kebingungan dan sulit untuk bicara. Penyakit stroke merupakan suatu penyakit yang berhubungan dengan aliran darah ke otak. Mengingat sedikitnya dokter spesialis saraf di berbagai daerah di Indonesia serta keterbatasan waktu dan tenaga seorang dokter dalam melayani masyarakat luas sehingga dibutuhkan sebuah sistem yang mampu membantu mendiagnosa penyakit stroke. Sistem pakar dapat memungkinkan orang awam bisa mengerjakan pekerjaan para ahli. Perhitungan ketidakpastian dalam sistem pakar dapat dilakukan dengan beberapa metode ketidakpastian. Case based reasoning merupakan sebuah paradigma utama dalam penalaran otomatis (automated reasoning) dan mesin pembelajaran (machine learning). Untuk mencari jarak terdekat dari tiap tiap kasus dan mencari ukuran kemiripan (similaritas) kasus lama dengan kasus baru, dalam penelitian ini menggunakan algoritma K-Nearest Neighbor dan algoritma similaritas probabilistic symmetric. Dalam penelitian ini, telah dibuat web aplikasi sistem pakar diagnosa penyakit stroke sehingga dapat membantu masyarakat/pengguna dalam mendiagnosa awal gejala penyakit stroke tanpa menemui seorang dokter.
\end{abstract}

Kata Kunci: Sistem Pakar, Case Based Reasoning, Penyakit Stroke, Probabilistic Symmetric, Web

\begin{abstract}
Stroke is one of the most dangerous diseases in Indonesia. Diseases that begin with signs such as numbness on the face, legs, arms, or on the side of one body, overcome with confusion and are difficult to talk. Stroke is a disease associated with blood flow to the brain. Considered by neurologists in various regions in Indonesia as well as limited time and doctors to serve the wider community, a system that is capable of diagnosing stroke is needed. Expert systems can enable ordinary people to do the work of experts. An assessment of the expert system can be done with several methods of replacement. Case based reasoning is the main paradigm in automatic reasoning and machine learning. To find the closest distance from each case and look for a measure of similarity of the old case with the new case, in this research using the K-Nearest Neighbor algorithm and probabilistic symmetrical probabilistic similarity algorithm. In this research, a web application expert system has been made to diagnose stroke so that it can help the user diagnose symptoms of a stroke without seeing a doctor.
\end{abstract}

Keywords: Expert System, Case Based Reasoning, Stroke Disease, Probabilistic Symmetric, Web

\section{Pendahuluan}

Kesehatan merupakan hal yang begitu penting bagi manusia. Ironisnya banyak penyakit yang pada akhirnya terlambat di diagnosa sehingga mencapai ke tahap kronis. Untuk itu diperlukan suatu sistem diagnosa penyakit meskipun didasarkan pada data yang kurang lengkap (Fanny, Hasibuan, \& Buulolo, 2017). Prevalensi penyakit stroke pada masyarakat di Indonesia berdasarkan diagnosa dokter menurut karakteristik, berdasarkan jenis kelamin laki-laki mencapai $11.0 \%$, perempuan mencapai $10.9 \%$, berdasarkan umur 15-24 : $0.6 \%$, umur $25-34: 1.4 \%$, umur $35-44: 3.7 \%$, umur $45-54: 14.2 \%$, umur $55-64: 32.4 \%$, umur $65-74: 45.3 \%$, umur $75 \geq: 50.2 \%$, dan berdasarkan daerah perkotaan $12.6 \%$, daerah perdesaan $8.8 \%$ (Riskesdas, 2018). 
Penyakit stroke merupakan salah satu penyakit yang cukup berbahaya di Indonesia. Penyakit yang diawali dengan tanda seperti mati rasa yang berada di wajah, kaki, lengan, ataupun di sisi salah satu tubuh, disertai dengan adanya kebingungan dan sulit untuk bicara. Berbicara tentang penyakit yang melumpuhkan bahkan mematikan penderitaanya ini sering diketahui ketika telah parah. Penyakit stroke merupakan suatu penyakit yang berhubungan dengan aliran darah ke otak. Biasanya penyakit stroke disebabkan oleh adanya pembuluh darah yang pecah atau terhambat oleh gumpalan darah (Kanggeraldo, Sari, \& Zul, 2018). Mengingat sedikitnya dokter spesialis saraf di berbagai daerah di Indonesia serta keterbatasan waktu dan tenaga seorang dokter dalam melayani masyarakat luas sehingga dibutuhkan sebuah sistem yang mampu membantu mendiagnosa penyakit stroke (Zainuddin, Hidjah, \& Tunjung, 2016).

Sistem pakar dapat memungkinkan orang awam bisa mengerjakan pekerjaan para ahli. Sistem pakar juga memiliki kemampuan untuk mengakses pengetahuan. Dan juga menghemat waktu dalam mengambil keputusan (Puspitasari, Susillo, \& Coastera, 2016). Perhitungan ketidakpastian dalam sistem pakar dapat dilakukan dengan beberapa metode ketidakpastian.

Untuk mencari jarak terdekat dari tiap tiap kasus dan mencari ukuran kemiripan (similaritas) kasus lama dengan kasus baru, dalam penelitian ini menggunakan algoritma $K$ Nearest Neighbor (K-NN) dan algoritma similaritas probabilistic symmetric. Logika pada algoritma similaritas probabilistic symmetric ini dapat membantu untuk mengambil keputusan dari permasalahan yang ada dengan keakuratannya melalui pernyataan-pernyataan yang diungkapkan dari pengetahuan yang tersedia. Metode ini sudah sering digunakan seperti pada dunia keuangan, sains dan berbagai disiplin ilmu lain (Aconcagua \& Wibisono, 2017).

Case Based Reasoning (CBR) adalah proses dalam mengingat suatu kasus pada masa lampau, lalu menggunakannya kembali dan mengadaptasikan dalam kasus baru. Tahapan-tahapan dalam (CBR) adalah sebagai berikut (Minarni, Warman, \& Handayani, 2017):

\section{Retrieve}

Mendapatkan/memperoleh kembali kasus yang paling menyerupai/relevan (similar) dengan kasus yang baru. Bagian ini mengacu pada segi identifikasi, kemiripan awal, pencarian dan pemulihan serta eksekusi.

\section{Reuse}

Reuse (menggunakan) informasi dan pengetahuan dari kasus tersebut untuk memecahkan permasalahan. Proses reuse dari solusi kasus yang telah diperoleh dalam konteks baru difokuskan pada dua aspek yaitu perbedaan antara kasus yang sebelumnya dan yang sekarang, bagian apa dari kasus yang telah diperoleh yang dapat ditransfer menjadi kasus baru.

\section{Revise}

Revise (meninjau/memperbaiki kembali) usulan solusi.

\section{Retain}

Retain (menyimpan) bagian-bagian dari pengalaman tersebut yang mungkin berguna untuk memecahkan masalah di masa yang akan datang.

Sistem inferensi yang akan digunakan untuk menghitung bobot kemiripan menggunakan algoritma K-Nearest Neighbor (K-NN).

$$
\begin{aligned}
& \begin{array}{l}
\text { Similarity }\left(\begin{array}{c}
\text { Problem, Case })= \\
\mathrm{S} 1^{*} \mathrm{~W} 1+\mathrm{S} 2^{*} \mathrm{~W} 2+\ldots . \mathrm{Sn} n^{*} \mathrm{Wn}
\end{array}\right. \\
\mathrm{W} 1+\mathrm{W} 2+\ldots \mathrm{Wn}
\end{array} \\
& \text { Keterangan: } \\
& \mathrm{S} \quad=\text { Similarity (nilai kemiripan) } \\
& \mathrm{W} \quad=\text { Weight (bobot yang diberikan) }
\end{aligned}
$$

Algoritma Probabilistic Symmetric merupakan logika yang mempelajari pernyataan-pernyataan yang bersifat pasti. Seperti halnya suatu penilaian terhadap hubungan antara pernyataan digit 0 dan 1 , yang mempunyai sifat tidak untuk nilai 0 dan ya untuk nilai 1 . Nilai 1 adalah nilai yang merepresentasikan suatu kemiripan mutlak, sedangkan nilai 0 merepresentasikan suatu ketidaksamaan mutlak. Rumus Algoritma Similaritas Probabilistic Symmetric terlihat pada persamaan 1 dan persamaan 2 (Aconcagua \& Wibisono, 2017).

$$
\begin{array}{r}
\mathrm{d}_{\text {PChii }}=2 \sum_{\mathrm{i}=1}^{\mathrm{d}} \frac{(\mathrm{Pi}-\mathrm{Qi})^{2}}{\mathrm{Pi}+\mathrm{Qi}} \\
\mathrm{S}=1-\sum_{\mathrm{i}=1}^{\mathrm{d}} \frac{(\mathrm{Pi}-\mathrm{Qi})^{2}}{\mathrm{Pi}+\mathrm{Qi}}
\end{array}
$$

\section{Keterangan:}

$$
\begin{array}{ll}
\mathrm{P} & =\text { Gejala yang telah dipilih pengguna } \\
\mathrm{Q} & =\text { Gejala yang telah disimpan pada } \\
& \text { basisdata } \\
\mathrm{d} & =\text { Jumlah atribut dalam setiap kasus } \\
\mathrm{i} & =\text { Atribut individu antara } 1 \text { sampai } \\
& \begin{array}{l}
\text { dengan } \mathrm{n} \\
\mathrm{S}
\end{array} \\
\mathrm{S} \text { Nilai similaritas } \\
\text { Berikut penelitian terkait dalam sistem }
\end{array}
$$
pakar. 
Pada penelitian (Zainuddin et al., 2016) dalam jurnalnya yang berjudul "Penerapan Case Based Reasoning (CBR) Untuk Mendiagnosis Penyakit Stroke Menggunakan Algoritma K-Nearest Neighbor" mengatakan bahwa berdasarkan hasil pengujian sistem CBR terhadap pakar untuk 15 kasus yang diuji sistem mampu mendiagnosis dengan tepat sesuai dengan hasil diagnosis pakar sebenarnya sebesar $93.3 \%$.

Pada penelitian (Aconcagua \& Wibisono, 2017) dalam jurnalnya yang berjudul "Case Based Reasoning Untuk Mendeteksi Hama dan Penyakit Tanaman Anggrek Dendrobium Menggunakan Algoritma Similaritas Probabilistic Symmetric" mengatakan bahwa metode Case Based Reasoning digunakan dalam aplikasi sistem pakar dengan menggunakan perhitungan algoritma Probabilistic Symmetric, dimana data kasus baru akan dibandingkan perhitungannya dengan data kasus lama yang ada di database, dan kemudian dihitung kriteria kemiripannya untuk menentukan nilai similaritas suatu penyakit yang dikonsultasikan.

Pada penelitian (Utomo \& Nasution, 2016) dalam jurnalnya yang berjudul "Sistem Pakar Mendeteksi Kerusakan Toner Dengan Menggunakan Metode Case BasedReasoning" mengatakan bahwa metode casebased reasoning merupakan salah satu algoritma dalam sistem pakar yang digunakan untuk mempermudah mendeteksi kerusakan toner.

Pada penelitian (Putri, Andreswari, \& Efendi, 2016) dalam jurnalnya yang berjudul "Implementasi Metode CBR (Case Based Reasoning) Dalam Pemilihan Pestisida Terhadap Hama Padi Sawah Menggunakan Algoritma K-Nearest Neighbor (KNN)" mengatakan bahwa pada pengujian ketika sistem dibangun hanya dengan melibatkan $80 \%$ data sebagai training dan $20 \%$ unseen instances sebagai data testing diperoleh hasil keakuratan verifikasi sebesar $95,83 \%$ yang artinya hampir semua data dapat dikenali.

Pada penelitian (Pahlawan \& Wibisono, 2017) dalam jurnalnya yang berjudul "Implementasi Case Based Reasoning Untuk Sistem Diagnosis Hama dan Penyakit Tanaman Cabe Merah Menggunakan Algoritma Similaritas Neyman" mengatakan bahwa sistem pakar untuk hama dan penyakit tanaman cabai merah menggunakan metode Case Based Reasoning dengan algoritma similaritas Neyman dapat digunakan masyarakat luas khususnya petani cabai merah untuk membantu mengetahui jenis hama dan penyakit tanaman cabai merah yang diderita.
Pada penelitian (Minarni et al., 2017) dalam jurnalnya yang berjudul "Case-Based Reasoning (CBR) Pada Sistem Pakar Identifikasi Hama Dan Penyakit Tanaman Singkong Dalam Usaha Meningkatkan Produktivitas Tanaman Pangan" mengatakan bahwa penelitian ini menghasilkan sistem pakar identifikasi hama dan penyakit tanaman pangan dengan metode inferensi case based reasoning dengan memperhitungkan kemiripan masalah baru dengan kasus lama.

Pada penelitian (Wijayanti \& Fadlil, 2014) dalam jurnalnya yang berjudul "Sistem Pakar Mendiagnosa Jenis Penyakit Stroke Menggunakan Metode Certainty Factor" mengatakan bahwa hasil dari pengembangan dan penelitian tersebut menghasilkan sebuah perangkat lunak baru yang mampu mendiagnosa jenis penyakit stroke berdasarkan gejala yang dimasukkan dan dapat memberikan informasi tentang penyakit yang terdiagnosa.

Pada penelitian (Gulo \& Syahrizal, 2018) dalam jurnalnya yang berjudul "Perancangan Aplikasi Sistem Pakar Mendiagnosa Penyakit Hemofilia Pada Manusia Menerapkan Metode Case Based Reasoning" mengatakan bahwa dengan menerapkan metode Case Based Reasoning dalam mendiagnosa penyakit hemofilia pada manusia dapat menghasilkan perhitungan yang sama dengan perhitungan manual sehingga proses diagnosa dapat dilakukan dengan cepat dan akurat.

\section{Metode Penelitian}

Algoritma yang akan diimplementasikan oleh penulis pada program sistem pakar ini yaitu di mulai dari proses tampilkan pertanyaan dan pilih gejala kemudian input dengan memilih gejala kemudian tampil suatu kemungkinan yang akan menghasilkan beberapa kemungkinan jawaban atau pilihan dan diakhiri dengan hasil diagnosa berikut dengan persentasenya. Untuk keterangan lebih jelas bisa dilihat pada gambar 1 . 


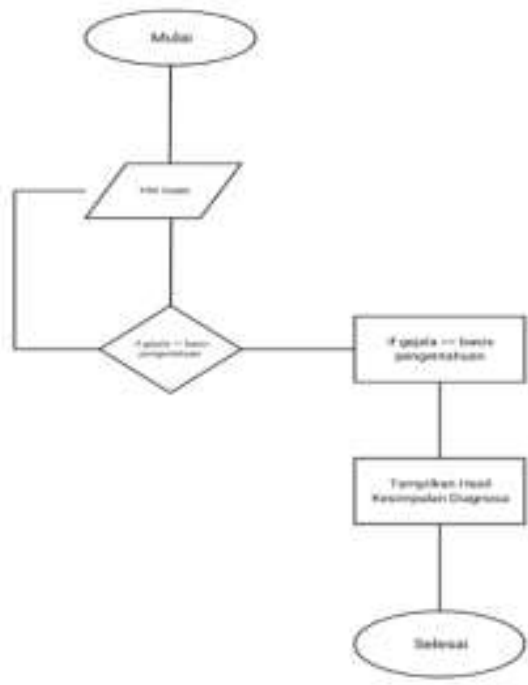

Sumber ( Hasil Penelitian )

Gambar 1. Algoritma program

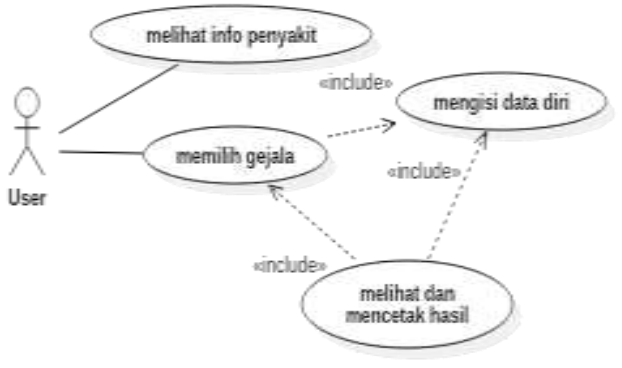

Sumber ( Hasil Penelitian )

Gambar 2. Use Case Diagram User

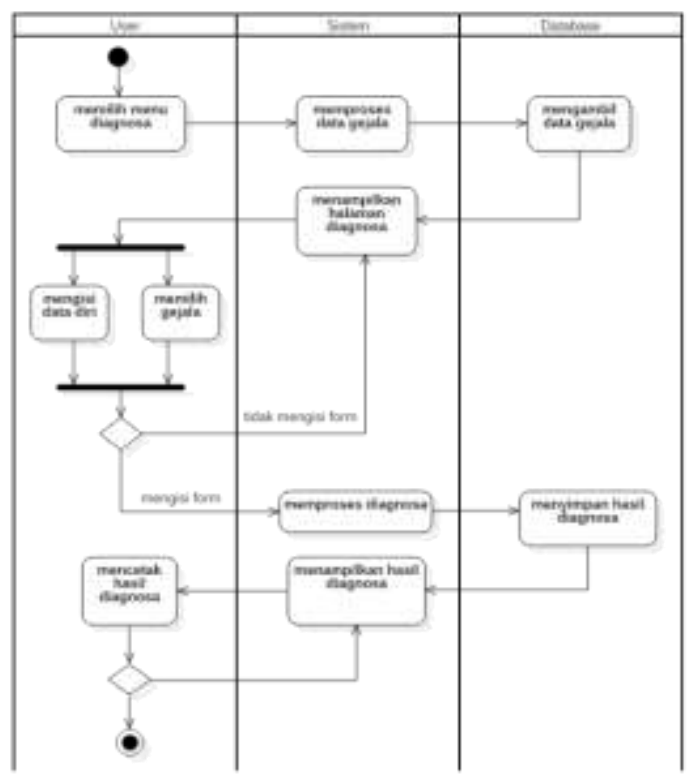

Sumber ( Hasil Penelitian )

Gambar 3. Activity Diagram User diagnosa

Berdasarkan rumus dari algoritma probabilistic symmetric, suatu penilaian terhadap hubungan antara pernyataan memiliki nilai 0 dan 1, yang mempunyai sifat tidak untuk nilai 0 dan ya untuk nilai 1 . Maka semua gejala memiliki nilai yang sama yaitu 1. Berikut keterangan penyakit,dan gejala pada tabel 1 .

Tabel 1. Keterangan penyakit dan gejala

\begin{tabular}{|c|c|}
\hline \multirow{11}{*}{$\begin{array}{c}\text { No } \\
1\end{array}$} & Gejala \\
\hline & Stroke Iskemik \\
\hline & $\begin{array}{l}\text { Wajah terkulai, terutama satu sisi wajah } \\
\text { terkulai atau mati rasa }\end{array}$ \\
\hline & $\begin{array}{lll}\text { Kelemahan lengan, } & \text { tidak mampu } \\
\text { mengangkat satu } & \text { lengan atau }\end{array}$ \\
\hline & $\begin{array}{l}\text { merasakan kelemahan atau mati rasa di } \\
\text { satu lengan }\end{array}$ \\
\hline & $\begin{array}{l}\text { Masalah bicara, seperti tidak dapat } \\
\text { berbicara atau mengulang kalimat }\end{array}$ \\
\hline & $\begin{array}{l}\text { Tidak mampu menggerakkan satu sisi } \\
\text { tubuh }\end{array}$ \\
\hline & $\begin{array}{l}\text { Sulit berjalan atau pusing, jatuh tanpa } \\
\text { sebab }\end{array}$ \\
\hline & $\begin{array}{l}\text { Kebingungan, tidak mampu memahami } \\
\text { ucapan }\end{array}$ \\
\hline & $\begin{array}{l}\text { Masalah penglihatan atau kesulitan } \\
\text { melihat }\end{array}$ \\
\hline & $\begin{array}{l}\text { Sakit kepala parah tanpa sebab yang } \\
\text { jelas }\end{array}$ \\
\hline \multirow[t]{9}{*}{2} & Stroke Hemoragik \\
\hline & Hilang kesadaran \\
\hline & Mual dan muntah \\
\hline & $\begin{array}{l}\text { Kebingungan atau kehilangan } \\
\text { kewaspadaan }\end{array}$ \\
\hline & $\begin{array}{l}\text { Masalah penglihatan atau kesulitan } \\
\text { melihat }\end{array}$ \\
\hline & $\begin{array}{l}\text { Kekakuan atau rasa sakit di daerah leher } \\
\text { Getaran tangan }\end{array}$ \\
\hline & $\begin{array}{l}\text { Sering berfluktuasi dalam detak jantung } \\
\text { dan pernapasan }\end{array}$ \\
\hline & Kesulitan menelan \\
\hline & $\begin{array}{l}\text { Wajah terkulai, terutama satu sisi wajah } \\
\text { terkulai atau mati rasa }\end{array}$ \\
\hline \multirow[t]{7}{*}{3} & Stroke Ringan / TIA (Transient \\
\hline & Gula darah rendah \\
\hline & Migra \\
\hline & Kejang ringan \\
\hline & Terkadang merasa \\
\hline & $\begin{array}{l}\text { Kem } \\
\text { Vert }\end{array}$ \\
\hline & in tangan \\
\hline \multirow[t]{7}{*}{4} & Stroke Brain Stem (Batang Otak) \\
\hline & \\
\hline & Kehilangan keseimbangan \\
\hline & Vertigo \\
\hline & $\begin{array}{l}\text { Masalah penglihatan atau kesulitan } \\
\text { melihat }\end{array}$ \\
\hline & Kesulitan bernafas sesaat \\
\hline & Kesulitan menelan \\
\hline
\end{tabular}


1. Rule 1

If Wajah terkulai, terutama satu sisi wajah terkulai atau mati rasa

And Kelemahan lengan, tidak mampu mengangkat satu lengan atau merasakan kelemahan atau mati rasa di satu lengan

And Masalah bicara, seperti tidak dapat berbicara atau mengulang kalimat dengan jelas

And Tidak mampu menggerakkan satu sisi tubuh

And Sulit berjalan atau pusing, jatuh tanpa sebab

And Kebingungan, tidak mampu memahami ucapan

And Masalah penglihatan atau kesulitan melihat

And Sakit kepala parah tanpa sebab yang jelas

Then Stroke Iskemik

2. Rule 2

If Hilang kesadaran

And Mual dan muntah

And Kebingungan atau kehilangan kewaspadaan

And Masalah penglihatan atau kesulitan melihat

And Kekakuan atau rasa sakit di daerah leher

And Getaran tangan

And Sering berfluktuasi dalam detak jantung dan pernapasan

And Kesulitan menelan

And Wajah terkulai, terutama satu sisi wajah terkulai atau mati rasa

Then Stroke Hemoragik

3. Rule 3

If Gula darah rendah

And Migrain

And Kejang Ringan

And Terkadang merasa kesemutan kemudian pingsan

And Vertigo

And Getaran tangan

Then Stroke Ringan / TIA (Transient Ischaemic Attack)

4. Rule 4

If Kejang ringan

And Kehilangan keseimbangan

And Vertigo

And Masalah penglihatan atau kesulitan melihat

And Kesulitan bernafas sesaat

And Kesulitan menelan

Then Stroke Brain Stem (Batang Otak)

\section{Hasil dan Pembahasan}

Untuk menentukan jenis penyakit stroke, terdapat perhitungan menggunakan metode Case Based Reasoning dengan algoritma K-Nearest Neighbor dan Probabilistic Symmetric. Misalkan pasien memilih gejala yang berdominan pada penyakit stroke iskemik. Beberapa gejala yang dipilih diantaranya:

1. Kelemahan lengan, tidak mampu mengangkat satu lengan atau merasakan kelemahan atau mati rasa di satu lengan

2. Masalah bicara, seperti tidak dapat berbicara atau mengulang kalimat dengan jelas

3. Kebingungan, tidak mampu memahami ucapan

4. Sakit kepala parah tanpa sebab yang jelas

3.1. Rumus K-Nearest Neighbor untuk mencari data gejala yang cocok dibagi jumah gejala penyakit

Similarity $($ Problem, Case $)=$

$\mathrm{S} 1{ }^{*} \mathrm{~W} 1+\mathrm{S} 2{ }^{*} \mathrm{~W} 2+\ldots . \mathrm{Sn}{ }^{*} \mathrm{Wn}$

$\mathrm{W} 1+\mathrm{W} 2+\ldots . \mathrm{Wn}$

Diketahui :

$\mathrm{S} \quad=$ Similarity (nilai kemiripan)

Sn =Jumlah gejala yang dipilih berdasarkan penyakit Stroke Iskemik yaitu 4

$\mathrm{W} \quad=$ Weight (bobot yang diberikan)

$\mathrm{Wn}=$ =Jumlah gejala pada penyakit Stroke Iskemik yaitu 8 gejala

Similarity $($ Problem, Case $)=1^{*} 1+1^{*} 1+1^{*} 1+1^{*} 1$

$1+1+1+1+1+1+1+1$

$=\underline{4}$

8

$=0.5$

3.2. Rumus disimilaritas probabilistic symmetric

$$
\mathrm{d}_{\text {PChii }}=2 \sum_{\mathrm{i}=1}^{\mathrm{d}} \frac{(\text { Pi-Qi) }}{2}
$$

Diketahui :

$\mathrm{P} \quad=$ Gejala yang telah dipilih pengguna

$\mathrm{Pi} \quad=$ Hasil perhitungan $K$-Nearest Neighbor

$\mathrm{Q}=$ Gejala yang telah disimpan pada basisdata

Qi $\quad=$ Nilai gejala yaitu 1

dpChii $=2 * \frac{(0.5-1) 2}{0.5+1}$

$=\frac{0.25}{1.5}$

$=0.1667$ 


$$
\begin{aligned}
& =2 * 0.1667 \\
& =0.3334
\end{aligned}
$$

\subsection{Rumus similaritas probabilistic} symmetric

$$
\begin{aligned}
& \mathrm{S}=1-\sum_{\mathrm{i}=1}^{\mathrm{d}} \frac{(\mathrm{Pi}-\mathrm{Qi})^{2}}{\mathrm{Pi}+\mathrm{Qi}} \\
& \begin{aligned}
\text { SpChii } & =1-0.3334 \\
& =0.6666
\end{aligned}
\end{aligned}
$$

3.4. Konversi hasil perhitungan dari similaritas probabilistic symmetric ke persen

$=$ similaritas probabilistic symmetric * 100

$=0.6666 * 100$

$=66.66 \%$

Berikut beberapa tampilan dari web aplikasi sistem pakar yang telah dibangun.

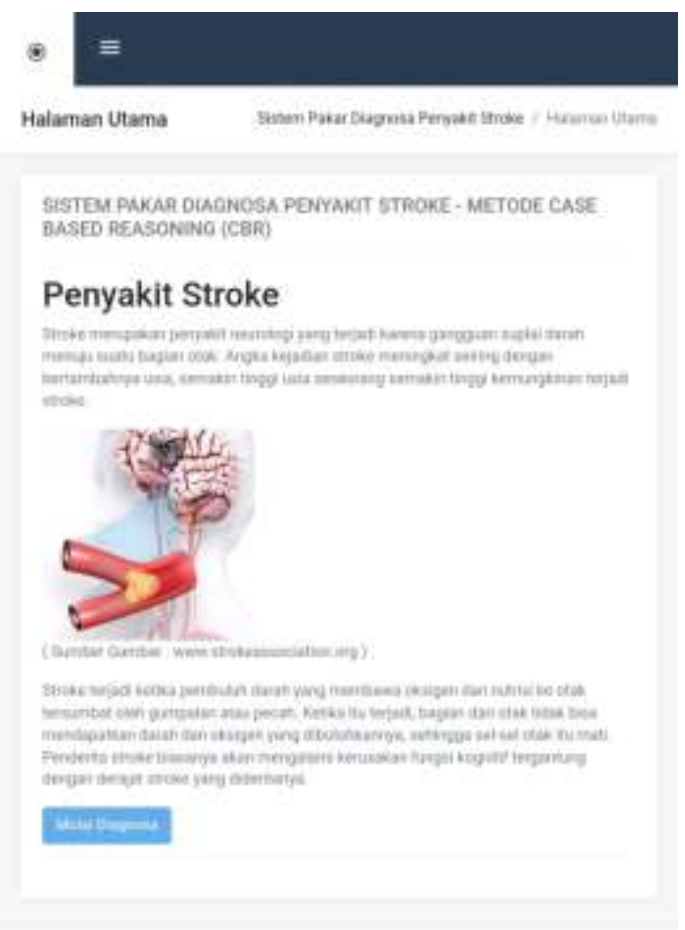

Gambar 4. Tampilan utama

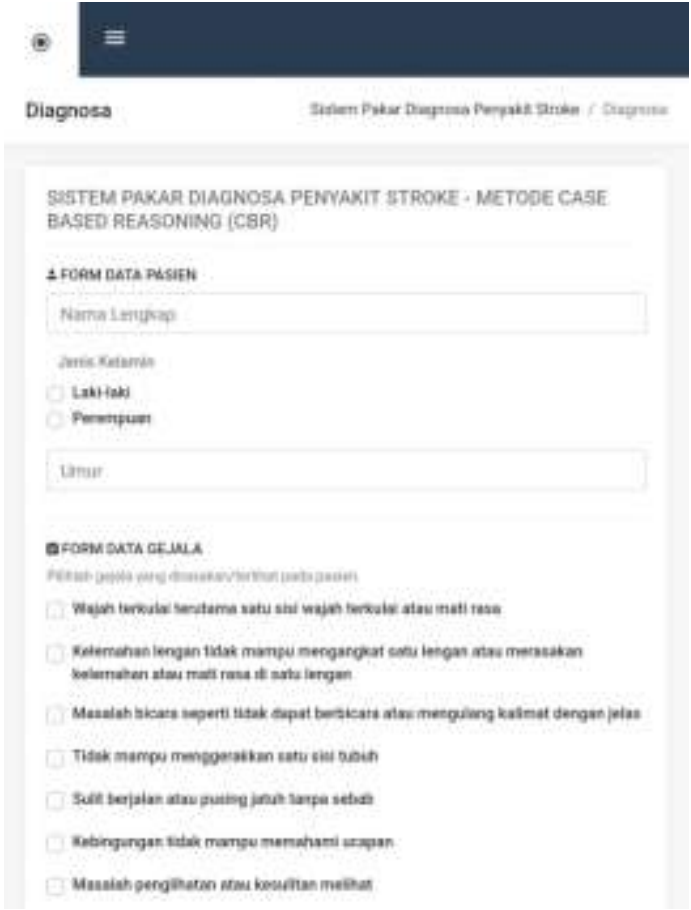

Gambar 5. Tampilan diagnosa

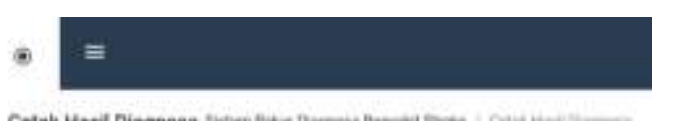

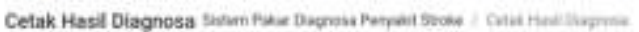

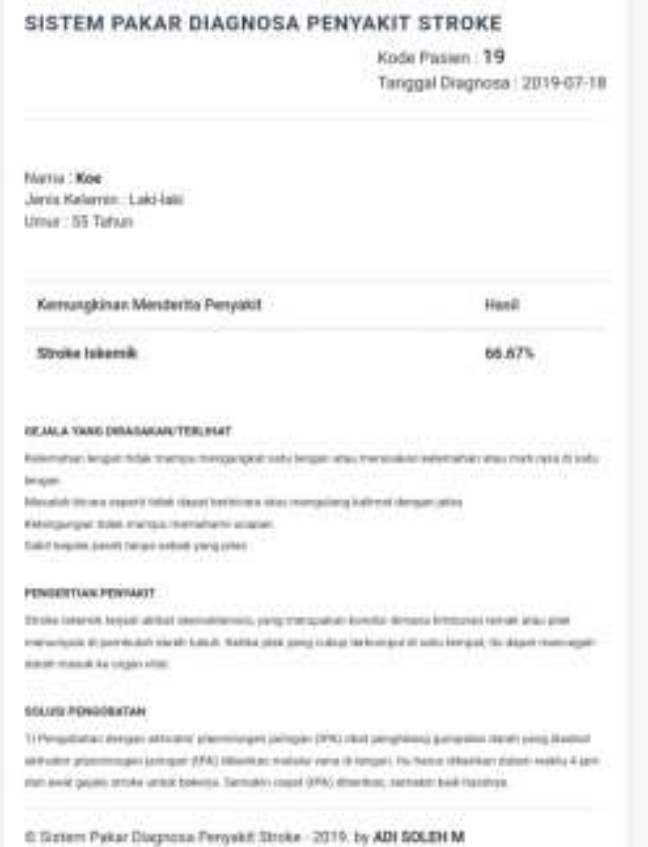

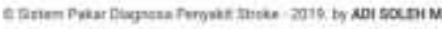

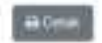

Gambar 6. Tampilan hasil diagnosa

\section{Kesimpulan}

Berdasarkan perhitungan menggunakan metode Case Based Reasoning dengan algoritma K-Nearest Neighbor dan Probabilistic Symmetric dapat disimpulkan 
bahwa dengan memilih gejala tersebut kemungkinan pasien menderita penyakit stroke iskemik dengan hasil perhitungan sebesar $66.66 \%$.

Dalam penelitian ini, dapat disimpulkan bahwa penggunaan metode Case Based Reasoning dan algoritma Probabilistic Symmetric pada sistem pakar dapat memperoleh hasil yang cukup akurat dalam mendiagnosa penyakit stroke.

\section{Referensi}

Aconcagua, P. A., \& Wibisono, S. (2017). Case Based Reasoning Untuk Mendeteksi Hama Dan Penyakit Tanaman Anggrek Dendrobium Menggunakan Algoritma Similaritas Probabilistic Symmetric. Prosiding SINTAK, 147-154.

Fanny, R. R., Hasibuan, N. A., \& Buulolo, E. (2017). Perancangan Sistem Pakar Diagnosa Penyakit Asidosis Tubulus Renalis Menggunakan Metode Certainty Factor Dengan Penelusuran Forward Chaining. Media Informatika Budidarma, 1(1), 13-16.

Gulo, A., \& Syahrizal, M. (2018). Perancangan Aplikasi Sistem Pakar Mendiagnosa Penyakit Hemofilia Pada Manusia Menerapkan Metode Case Based Reasoning. Pelita Informatika, 17(1), 2429.

Kanggeraldo, J., Sari, R. P., \& Zul, M. I. (2018). Sistem Pakar Untuk Mendiagnosis Penyakit Stroke Hemoragik dan Iskemik Menggunakan Metode Dempster Shafer. Jurnal RESTI (Rekayasa Sistem Dan Teknologi Informasi), 2(2), 498-505. https://doi.org/10.29207/resti.v2i2.268

Minarni, Warman, I., \& Handayani, W. (2017). Case-Based Reasoning (Cbr) Pada Sistem Pakar Identifikasi Hama Dan Penyakit Tanaman Singkong Dalam Usaha Meningkatkan Produktivitas Tanaman Pangan. 5(1), 41-47. https://doi.org/10.21063/JTIF.2017.V5.1.4 $1-47$
Pahlawan, A., \& Wibisono, S. (2017). Implementasi Case Based Reasoning Untuk Sistem Diagnosis Hama Dan Penyakit Tanaman Cabe Merah Menggunakan Algoritma Similaritas Neyman.

Puspitasari, T., Susillo, B., \& Coastera, F. (2016). Implementasi Metode DempsterShafer dalam Sistem Pakar Diagnosa Anak Tunagrahita Berbasis Web. Jurnal IImiah Teknik Informatika, 4(1), 1-13.

Putri, T., Andreswari, D., \& Efendi, R. (2016). Implementasi Metode CBR (Case-Based Reasoning) Dalam Pemilihan Pestisida Terhadap Hama Padi Sawah Menggunakan Algoritma K-Nearest Neighbour (K-NN) (Studi Kasus Kabupaten Seluma). Jurnal Rekursif, Universitas Bengkulu, 4(1), 80-92.

Riskesdas. (2018). Hasil Utama Riset Kesehatan Dasar. Kementrian Kesehatan Republik Indonesia, 1(1), 1-200. https://doi.org/1 Desember 2013

Utomo, D. P., \& Nasution, S. D. (2016). Sistem Pakar Mendeteksi Kerusakan Toner Dengan Menggunakan Metode Case Based-Reasoning. Jurnal Riset Komputer (JURIKOM), 3-6.

Wijayanti, P., \& Fadlil, A. (2014). SISTEM PAKAR MENDIAGNOSA JENIS PENYAKIT STROKE MENGGUNAKAN METODE CERTAINTY FACTOR. 2, 691700.

Zainuddin, M., Hidjah, K., \& Tunjung, I. W. (2016). Penerapan Case Based Reasoning (CBR) Untuk Mendiagnosis Penyakit Stroke Menggunakan Algoritma K-Nearest Neighbor. 21-26. 